\title{
A comprehensive exploration of Java man: bio-cultural evolution from Homo Erectus to Homo Sapiens
}

\author{
Samuel J Haryono ${ }^{1,2^{*}}$, Sri Utami ${ }^{3}$, Restu Ambar Rahayuningsih ${ }^{1,2}$ \\ ${ }^{1}$ Ullen Sentalu Museum, ${ }^{2}$ Gadjah Mada University, ${ }^{3}$ Vivo Research Initiative \\ DOI: http://dx.doi.org/10.19106/JMedScieSup0048042016024
}

\begin{abstract}
An overlap of time period between Homo erectus and Homo sapiens has not been confirmed. There are two missing links in human history, i.e. between man and ape and between the progressive Homo erectus and archaic Homo sapiens. Specimen dating on Java Man has been discrepant among research groups, and the use of molecular biology in ancient specimens is a novelty. This study intends to use fossilised specimens to harvest and sequence the DNA for ribosomal analysis and formulating comparative phylogeny among ancient man, modern man, and other hominids. We aimed to reconstruct the evolution pathway, the phylogenetic tree between ancient and modern hominids, and discover the uniqueness of Homo sapiens sapiens. Dental calculus was analysed to identify starch, carbohydrate, and protein to illustrate paleo dietary pattern. Soil samples were examined for pollen and phytoliths to elaborate on ancient ecosystem. Blood samples were procured from indigenous people along the riverflow region of Bengawan Solo to analyse modern human DNA.
\end{abstract}

Keywords: Java Man, Ribosomal DNA, Hominid Phylogenetic

Corresponding author: samuelharyono@yahoo.com 